\title{
Ik OnIk TRANSFORMASI WAYANG BEBER DALAM BATIK LUKIS
}

Volume 2, Nomor 2

Juli 2020,

(51-56)

\author{
Stefanus Bintang Kumara \\ Jurusan Seni Kriya, Program Penciptaan dan Pengkajian \\ Pascasarjana Institut Seni Indonesia Yogyakarta \\ e-mail : kumarabintang12@gmail.com
}

\begin{abstract}
ABSTRAK
Wayang beber merupakan salah satu artefak budaya Nusantara yang berasal dari Jawa, hingga saat ini wayang beber asli masih dijaga keberadaannya dengan baik. Namun dengan berkembangnya zaman, wayang ini kurang diminati oleh masyarakat dan lebih cenderung memilih produk atau hiburan yang lebih modern. Fenomena tersebut memantik untuk berupaya mempopulerkan dan memperkenalkan kembali wayang beber dengan mengembangkan bentuk visual, tampilan, hingga material. Tujuan penciptaan ini adalah mengembangkan seni tradisi wayang beber melalui media batik dan mewujudkan bentuk visual baru dalam wayang beber. Penciptaan karya dimulai dari pembuatan sketsa perancangan, persiapan alat, bahan, hingga sampai ke proses perwujudan dengan menggunakan teknik tutup celup, lorodan. Tahap berikutnya pemindahan sketsa pada kain, pencantingan, pewarnaan, pelorodan, dan display. Pada proses penciptaan ini diperkuat oleh teori-teori pendukung, yakni teori transformasi dan adaptasi. Karya yang dihasilkan dalam penciptaan ini adalah batik lukis dengan ide wayang beber Pacitan (Joko Kembang Kuning). Karya batik ini mengembangkan bentuk visual dari wayang Pacitan dan mengadopsi adegan cerita pada gulungan gambar. Bentuk figur, warna, komposisi dikembangkan sehingga terdapat bentuk pembeda dari gambar wayang asli. Batik lukis dengan ide wayang beber Pacitan dibuat agar menambah daya tarik masyarakat akan wayang beber, serta memberikan pengetahuan akan pentingnya kesenian budaya Indonesia.
\end{abstract}

Kata Kunci : Batik Lukis, Transformasi, Wayang Beber

\begin{abstract}
The wayang beber is one of the archipelago cultural artifacts originating from Java, until now the original wayang beber still is well preserved. However with the development of the times, this wayang is less attractive to the public and more likely to choose products or entertainment that is more modern. This phenomenon triggers to attempt to popularize and reintroduce wayang beber by developing visual forms, appearance, and material. The purpose of this creation is to develop the art of the wayang beber tradition through batik media and to realize new visual forms in the wayang beber.The creation of this work starts from the making of design sketches, preparation of tools, materials, up to the embodiment process using the technique of dyeing, lorodan. The next step is sketch transfer to fabric, coloring, pelorodan, and display. In the process of creation this is reinforced by supporting theories, namely the theory transformation and adaptation. The workproduced in this creation is apainting with the idea of wayang Pacitan (Jok Kembang Kuning). This batik work develops the visual form of the wayang Pacitan and adopts a story scene on a picture roll. Figure shapes, colors, compositions are developed so there are distinguishing forms from original wayang picture. Batik painted with the idea of Pacitan wayang beber was made in order to add to the appeal of the public about wayang beber, as well as providing knowledge of the importance of indonesian cultural arts.
\end{abstract}

Keywords: Batik Painted, Transformation, Wayang Beber,

\section{PENDAHULUAN}

Indonesia memiliki kebudayaan beragam bentuk dan tradisi yang terkandung di dalamnya, wang misalnya. Wayang merupakan salah satu seni tradisi yang dilestarikan keberadaannya. Figur wayang adalah sebuah gambar diri dari perilaku manusia, memunyai berbagai bentuk sifat, seperti baik buruk, benar salah, dan sifat lainnya. Oleh karena itu seiring berkembangnya zaman wayang diperuntukan sebagai media dakwah yang bersifat menghibur dan memberikan pesan moral didalamnya. Melalui figur pewayangan dapat diartikan bahwa, wayang menggambarkan kebudayaan Jawa. Sehingga wayang dipandang oleh masyarakat sebagai hiburan sekaligus tuntunan. Salah satu ciri manusia sebagai makhluk yang berbudaya yaitu 
dengan memahami nilai yang terkandung dalam budaya tersebut dan sekaligus mampu mewujudkannya melalui sebuah karya dari hasil pemaknaan dan penghayatan yang mendalam berdasarkan budaya yang mengakar (Ernawati, 2019). Salah satu upaya pendalaman makna atau nilai kesenian wayang dapat dilakukan dengan mempelajarinya dan mewujudkannya melalui karya seni.

Kesenian wayang menjadi salah satu bagian dari kehidupan masyarakat di Indonesia. Wayang juga merupakan kesenian yang dikenal oleh berbagai Negara sebagai salah satu seni tradisi/kebudayaan yang Indonesia miliki. Banyak macam wayang yang terdapat di Nusantara dengan berbagai ciri khas dan keunikan yang berbeda-beda. Seni wayang akan terus tumbuh berkembang atas dukungan masyarakat. Kesadaran itulah mendukung wayang tetap ada di Indonesia. Tetapi ada yang semakin jarang atau langka keberadaannya, karena mulai dilupakan oleh masyarakat pendukungnya. Seperti wayang beber, wayang ini merupakan seni pertunjukan wayang yang menggunakan gambar-gambar yang bercerita. Ceritanya pun dituturkanoleh dalang dan diiringi gamelan. Dalang membuka gulungan gambar satu-persatu sesuai alur cerita yang dibawakan. Gambar terse3but di letakkan di atas peti kecil dengan cara dibeberkan atau dibentangkan.

Kesenian wayang beber salah satu kesenian yang dinanti-nanti atau menjadi tontonan yang paling ditunggu oleh masyarakat Jawa pada abad ke-13, yakni pada masa kerajaan Majapahit (sayid R.M,1980). Seiring perkembangan zaman, wayang beber sudah semakin jarang dan langka pementasannya. Kelangkaan ini dikarenakan masyarakat jenuh sehingga lebih tertarik dengan kesenian lain. Pengaruh teknologi juga mempengaruhi kurangnya minat masyarakat akan wayang beber. Kemajuan teknologi informasi dan komunikasi telah mengubah pemikiran masyarakat terhadap bebrbagai kegiatan atau pekerjaan yg lebih menghasilkan.

Wayang beber tertua terdapat di dua daerah, yaitu di Pacitan dan Wonosari. Kedua wayang ini menjadi sebuah acuan atau sumber ide bagi masyarakat untuk mengembangkan dan mengenal seni wayang beber. Pada proses penciptaan ini, penulis mengacu pada bentuk visual wayang Pacitan. Wayang beber Pacitan memiliki visual menarik dan dipenuhi dengan ornament, sehingga komposisi wayang ini terlihat padat. Proses penciptaan ini menstranformasi beberapa potongan adegan yang nantinya akan di visualisasikan dalam media batik lukis. Transformasi tersebut tidak hanya memindahkan media saja, namun juga pada pengembangan bentuk anatomi dari wayang Pacitan. Hal ini bertujuan agar wayang beber mengalami sebuah pengembangan dari bentuk hingga material.

Wayang beber saat ini sedikit peminatnya, sehingga wayang ini jarang sekali dipentaskan. Fenomena tersebut jika dibiarkan terlalu lama akan berdampak buruk, karena terjadi hilangnya unsur kesenian tradisi budaya bangsa Indonesia. Walaupun demikian masih sedikit masyarakat yang ikut andil dalam pelestarian wayang tersebut. Berangkat dari keprihatinan akan wayang beber, muncullah upaya peduli terhadap seni tersebut. Hal yangb perlu dilakukan seperti mengembangkan bentuk wayang beber dengan bentuk baru dengan hasil batik lukis.

Melihat keprihatinan wayang beber memantik penulis untuk melakukan pengembangan/inovasi guna mewujudkan atau menampilkan bentuk berbeda dari yang sudah perna ada. Memindah dan mengubah media wayang beber ke dalam batik lukis menjadi suatu inovasi yang menarik. Oleh karna itu dalam pembuatann karya ini, penulis akan membahas tentang proses pembuatan batik lukis dengan ide dan pengembangan visual wayang beber.

\section{METODE PENCIPTAAN}

Metode dalam pembuatan karya seni memiliki peranan penting dalam proses berkarya, agar lebih terstruktur atau sistematis. Selain itu teori yang tepat akan membantu dalam menguraikan permasalahan di dalam karya tersebut. Pada penciptaan ini menggunakan dua teori yaitu transformasi dan adaptasi. Teori transformasi mengacu pada perubahan bentuk dengan cara memindahkan wujud atau figur objek ke dalam objek yang digambar. (Kartika, 2017:39). Transformasi dilakukan tidak hanya sekedar memindah, namun juga mengembangkan bentuk figur serta objek yang terdapat pada wayang beber Pacitan.

Pendekatan adaptasi menurut definisinya mengubah, menyesuaikan, mencocokan (Hutcheon, 2006:7). Dapat diartikan adaptasi adalah sebuah cara dalam menggambarkan kembali atau mewujudkan kembali sesuatu yang sudah ada dengan bentuk yang berbeda. Karya dengan pendekatan adaptasi tidak seutuhnya sama dengan bentuk aslinya. Karya adaptasi juga tergantung pada interpretasi dan imajinasi dari si senimannya. Pada penciptaan ini mengadopsi wayang beber Pacitan sebagai sumber ide pencapaian karya batik lukis, yang mana proses pembuatannya dirubah, disesuaikan, dan dipindah dengan hasil akhir batik lukis.

Demi mempermudah proses pembuatan karya, penulis menggunakan metode penciptaan yang dikemukakan oleh Gustami yaitu eksplorasi, perancangan, perwujudan (Gustami, 2004). 
Eksplorasi yaitu tahapan pencarian terhadap bentuk-bentuk, material, serta teknik yang akan dipilih untuk pembuatan karya. Perancangan merupakan sebuah tahapan dimana seniman mulai merancang karya dengan pembuatan sketsa, pada tahap ini dilakukan pemilihan bentuk dengan tepat dari berbagai alternatif sketsa yang dibuat. Perwujudan yaitu proses pembuatan karya seni yang diawali dari persiapan alat dan bahan, lalu ketahap pemolaan hingga pelorodan.

\section{HASIL DAN PEMBAHASAN}

\section{Wayang beber}

Wayang beber merupakan wayang tertua yang terdapat di Indonesia (lebih tua dari wayang kulit). Wayang ini adalah salah satu jenis wayang yang berada di daerah Jawa, berbahan baku kertas dan digambar menurut adegan cerita serta dipentaskan berupa pertunjukan gambar yang dibentang. Terdapat beberapa bagian gambar atau gulungan yang membedakan setiap adeganadegan/kejadian dalam cerita yang diangkat. Biasanya cerita yang diusung merupakan cerita rakyat yaitu cerita-cerita Panji.

Sejauh ini wayang beber masih belum diketahui dengan pasti kapan awal munculnya, tetapi para ahli mengemukakan bahwa wayang beber memiliki usia yang sudah tua. Pada awalnya wayang beber mengisahkan cerita wayang purwa atau cerita Mahabarata (Subandi, 2011:3). Saat ini masih terdapat dua artefak wayang beber tertua yang berada di Jawa, yaitu di daerah Pacitan dan Wonosari. Kedua artefak ini masih disimpan dan dirawat dengan baik oleh keturunan dari dalang terdahulu. Ceritanya pun sama mengusung cerita Panji hanya saja penyajian dalam gambarnya berbeda serta penyampaian ceritanya pun mengalami perbedaan. Perubahan atau perbedaan cerita pada wayang beber merupakan variasi/improvisasi dari dalang itu sendiri agar terlihat lebih menarik.

Fungsi wayang beber pada dasarnya sebagai sebuah pertunjukan di sebuah upacara adat seperti ruwatan atau kegiatan-kegiatan yang memperingati sebuah peristiwa, seperti : peringatan tujuh bulanan, perkawinan atau temanten, bersih desa, kelahiran bayi, syukuran atas melimpahnya panen, dll. Pada umumnya pertunjukan wayang beber untuk menetralisir halhal yang bersifat negatif yang akan menimpa (Subandi: 2011:20-23)

Saat ini wayang beber mengalami perkembangan yang begitu pesat, dari material hingga penyajiannya. Penyajian yang dimaksud meliputi : bentuk visual, anatomi, cerita yang diangkat, dan tampilan. Pada awalnya pembuatan wayang beber dikerjakan diatas daun rontal kering. Berkembangnya zaman wayang beber dipindah ke dalam bahan kertas. Menurut sejarahnya dalam bahasa Jawa kertas dinamakan dluwang. Dluang merupakan kertas kuno yang dibuat secara kusus dan manual dari serat kulit pohon galigo atau pohon saeh (Subandi,2011:24)

Gambar yang dibuat material kertas lebih terlihat jelas dari pada menggunakan daun rontal. Waktu itu warna wayang beber masih belum berwarna, hanya hitam putih saja berupa kontur pada objek gambar. Ketika memasuki era Majapahit wayaang beber sudah mulai diberi warna dengan menggunakan pewarna alam. Teknik dalam pewarnaannya pun menggunakan teknik sungging. Warna yang dihasilkan masih sederhana seperti merah, coklat, hijau dan kuning (Sayid.R.M, 1980)

Bertambahnya waktu wayang beber sudah diterapkan atau dibuat dengan menggunakan kain kanvas sebagai material utama serta pewarna sintetis. Penggunaan kain kanvas bertujuan agar lebih awet dan tidak mudah sobek. Pewarna sintetis juga dipakai agar warna yang dihasilkan cerah dan dapat menghasilkan berbagai warna. Pemaparan tersebut merupakan bukti bahwa wayang beber mengalami sebuah perkembangan dari segi material, juga memiliki sifat dinamis yang akan terus berkembang dari zaman ke zaman.

Bentuk wayang beber sudah mulai mengalami perkembangan dan kebaruan yang cukup signifikan. Pengembangan material hingga bentuk memacu masyarkat kususnya seniman maupun pengrajin untuk berfikir kreatif. Berbagai model dibuat agar dapat menghasilkan wayang beber baru atau adanya pembeda dari wayang beber sebelumnya. Kebaruan itu meliputi segi visual, bentuk, bahan, warna, serta fungsi.

Pada ide penciptaan batik lukis ini, Wayang beber Pacitan menjadi sumber ide dalam pembuatannya dengan mengolah adegan cerita serta dikembangkan komposisi, warna dan bentuk figur. Wayang beber Pacitan diyakini oleh para ahli merupakan salah satu wayang beber asli (tertua). Dalam cerita pewayangannya hanya memiliki satu tokoh utama atau lakon yakni Jako Kembang Kuning. Lakon Joko Kembang Kuning terdiri dari 24 penjagongan atau adegan digambarkan dalam 6 gulungan kertas. Kisah ceritanya merupakan sebuah pengembaraan Raden Panji yang menyamar untuk memenangkan sebuah sayembara untuk mendapatkan Dewi Sekartaji (Sumanto,2011:65-66).

Adegan wayang Pacitan menjadi acuan atau sumber ide dalam penciptaan karya seni ini. Pengembangan bentuk visual yang dilakukan tidak terlepas dari ciri khas wayang beber Pacitan. Perbedaannya pun akan terlihat dari segi bentuk, tampilan, warna, komposisi dari wayang aslinya. Pengembangan bentuk hingga material diwujudkan dalam karya ini agar mendapatkan 
bentuk-bentuk baru, supaya tidak ada kemiripan bentuk dari karya wayang yang sudah ada.

\section{Batik}

Pengertian batik adalah gambar berpola atau membuat corak dengan menuangkan malam pada kain dengan alat bantu canting. Batik merupakan sebuah bentuk seni tradisional yang lahir turun-temurun dan merupakan sebuah kebudayaan lokal indonesia. Seni tradisi batik adalah salahsatu kesenian indonesia yang diakui oleh UNESCO sebagai warisan budaya dunia. Batik memiliki sifat yang terbilang fleksibel atau mudah diterapkan diberbagai bidang yaitu dapat diterapkan sebagai karya fungsional maupun non fungsional atau karya seni.

Batik sudah mengalami sebuah perkembangan yang pesat dari bentuk hingga material. Keberagaman teknik, corak/motif, diwujudkan dengan bentuk baru. Kebaruan ini hadir karena melihat berbagai aspek/fenomena kehidupan saat ini. Pada dasarnya batik saat ini sudah mulai bebas dan tidak terpengaruh oleh pakem-pakem batik tradisional. Batik yang bebas dalam mengekspresikan bentuk atau objek yaitu batik lukis. Batik lukis ini juga dapat mengkombinasikan berbagai teknik dalam batik dan bebas dalam menggoreskan lilin malam pada kain. Karya seperti itu juga sering disebut batik modern.

Menurut Susanto (1980: 15) batik modern ialah semua macam jenis batik yang motif dan gayanya tidak seperti batik tradisional. Sedangkan pada batik tradisional motif/coraknya masih terpaku pada pakem tertentu. Warna yang dihasilkan batik modern lebih beragam tidak seperti batik tradisional yang warnanya cenderung gelap seperti coklat, biru tua, hitam. Pada batik modern ini memiliki berbagai teknik dalam pengerjaannya, yaitu teknik kerok, tutup celup, lorodan, dan lain-lain. Banyak teknik yang bisa dipakai, kembali lagi pada si pembuatnya bagaimana memanfaatkan teknik yang sudah ada. Pada penciptaan karya seni ini penulis ini ingin membuat batik lukis dengan ide dan tema wayang beber Pacitan (Joko Kembang Kuning) dengan mengunkan teknik tutup celup dan lorodan.

\section{KONSEP PERANCANGAN}

Konsep perancangan merupakan penggabungan antara kedua warisan budaya Indonesia yaitu wayang beber dan batik. Wayang beber menjadi sumber ide dalam pembuatan karya batik lukis. Merancang sebuah karya seni tidak terlepas dari pencarian data yang mendukung proses penciptaan kaya ini. Pencarian data dilakukan dengan mengamati secara langsung bentuk-bentuk atau karya wayang beber terdahulu hingga saat ini. Karya-karya lain selain wayang beber juga dapat menjadi sebuah acuan dalam perwujudan karya seni asalkan tidak melenceng dari tema yang diangkat. Setelah mendapatkan data tersebut lalu mengevaluasi dan menganalisis kembali sesuai tema yang dibuat.

Pada pengumpulan data ada aspek yang harus dipertimbangkan dalam melakukan penerapan wayang beber pada media batik. Aspek estetis dari karya ini adalah bagaimana mengolah atau mengembangkan karakter visual pada wayang beber tanpa mengurangi ciri khas dari wayang beber tersebut. Karya batik ini sumber idenya mengacu pada wayang beber Pacitan. Dalam proses pembuatannya penulis hanya mengambil bagian dari alur cerita Joko Kembang Kuning (wayang Pacitan), lalu divisualisasikan dalam batik lukis.

Teknik yang digunakan dalam penciptaan karya ini adalah teknik batik tutup celup dan lorodan. Teknik tutup celup ini merupakan teknik klasik pada proses pembuatan batik, dimana kain yang sudah dicelup warna kembali dicanting atau di tutup malam kembali. Proses ini dilakukan hingga warna terakhir atau yang diinginkan lalu dilorod (menghilangkan lilin malam). Teknik lorodan juga merupakan teknik dalam pembuatan batik. Pada umumnya hanya proses menghilangkan lilin malam, tetapi setelah menghilangkan lilin masih mengalami proses penutupan dan pencantingan. Pelorodan ini dapat dilakukan tidak hanya satu kali bisa 2-4 kali. Jika kedua teknik itu digunakan warna yang dihasilkan beragam dan dapat membuat efek seperti gelap terang, bayangan, tekstur.

Tahap pencarian bentuk dimulai dari pembuatan sketsa. Sketsa pengembangan terus dilakukan hingga mendapatkan bentuk yang tepat dan sesuai dalam cerita yang diusung. Penciptaan ini mengambil cerita wayang beber Pacitan yaitu cerita Panji Joko Kembang kuning. Mengambil beberapa adegan dalam cerita tersebut dan divisualisasikan kedalam media batik. Bentuk dari figur tokohnya tidak terlepas dari cerita aslinya, hanya saja komposisi dan settingannya dibuat berbeda dengan wayang asli (wayang Pacitan).

Proses penciptaan karya ini diperlukan data acuan mengenai wayang beber kususnya wayang Pacitan untuk mempermudah dalam proses pembuatan karya dan sebagai pembuktian adanya ketertarikan dengan refrensi tersebut. Data dapat diperoleh dari berbagai sumber seperti : majalah, museum, internet, buku-buku wayang. Sebagai berikut: 


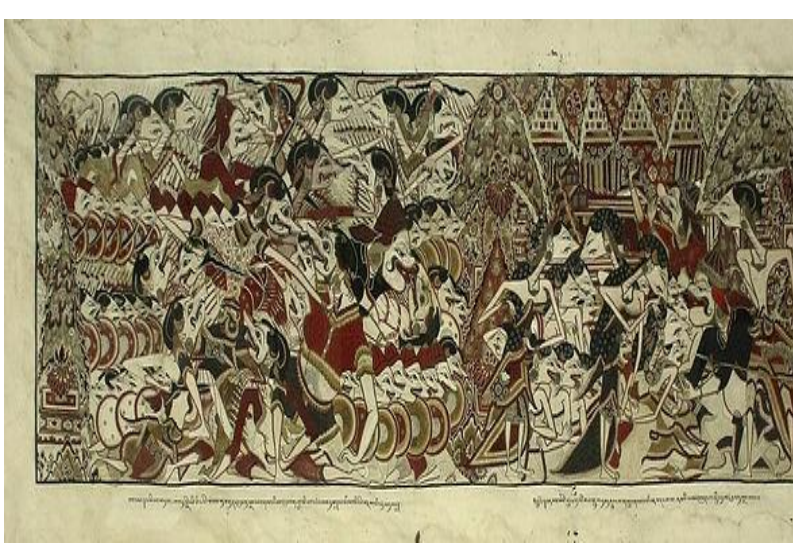

Gambar 1 : Wayang beber Pacitan

Sumber : http://ringgit-

wacucal.blogspot.com/2012/01/wayangbeber.html

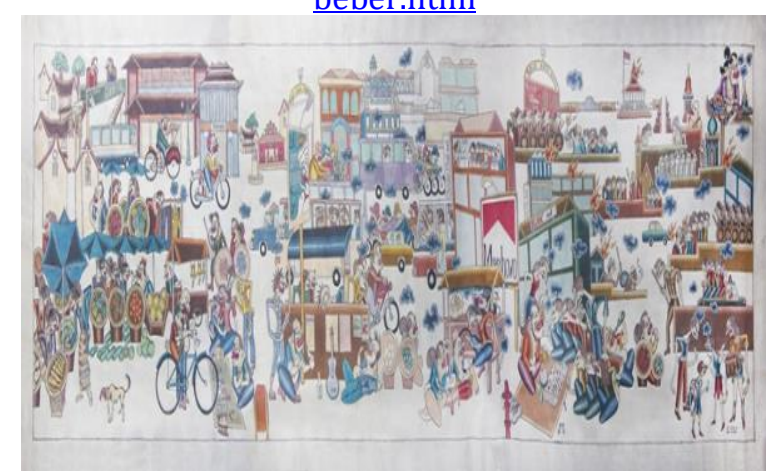

Gambar 2 : Wayang beber kota, karya Dani Iswardana Wibowo

Sumber :

https://wayangbeberproject.wordpress.com/

\section{HASIL DAN PEMBAHASAN}

Berikut ini merupakan proses perancangan yang diawali dengan membuatan sketsa figur tokoh pewayangan :

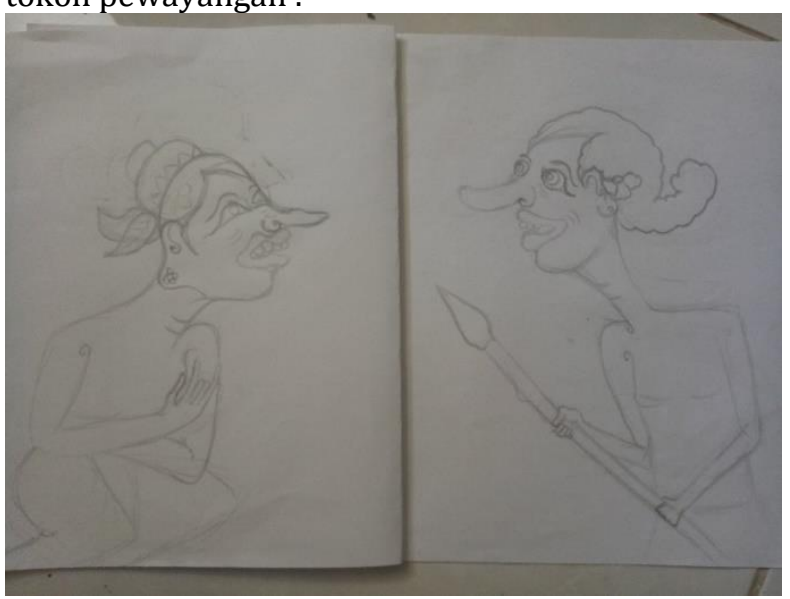

Gambar 3 : sketsa figur wayang

Dokumentasi : Stefanus Bintang Kumara, 2018

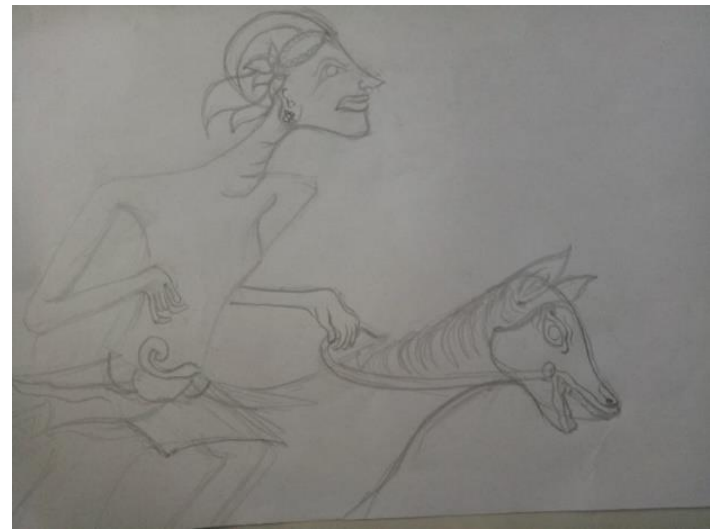

Gambar 4 : sketsa tokoh Panji Dokumentasi :Stefanus Bintang Kumara, 2018

Karya ini diwujudkan dalam bentuk batik lukis dengan teknik tutup celup dan lorodan. Pewarnaan yang digunakan pada penciptaan ini menggunakan pewarna napthol dan indigosol. Kedua warna tersebut memiliki perbedaan diantaranya yaitu napthol memiliki warana lebih cenderung pekat atau kuat, sedangkan indigosol warnanya lebih lembut dan transparan. Dalam pengerjaan dengan pewarna tekstil ini dibutuhkan eksperimen warna yang bertujuan supaya tidak terjadi kesalahan saat proses pencelupan.

Prose pembuatan batik tidak terlepas dari alat yang mendukung dalam pembuatan karya seni, yaitu kompor, wajan, canting, kuas, ember, dan tong. Beberapa alat itulah yang mendukung tahap pengerjaan batik. Ada beberapa tahap yang harus dipahami dalam pembuatan karya seni batik, diantaranya yaitu : tahap pemolaan, tahap kedua pencantingan dan penutupan, tahap ketiga pewarnaan, dan ke empat pelorodan.

\section{KARYA}

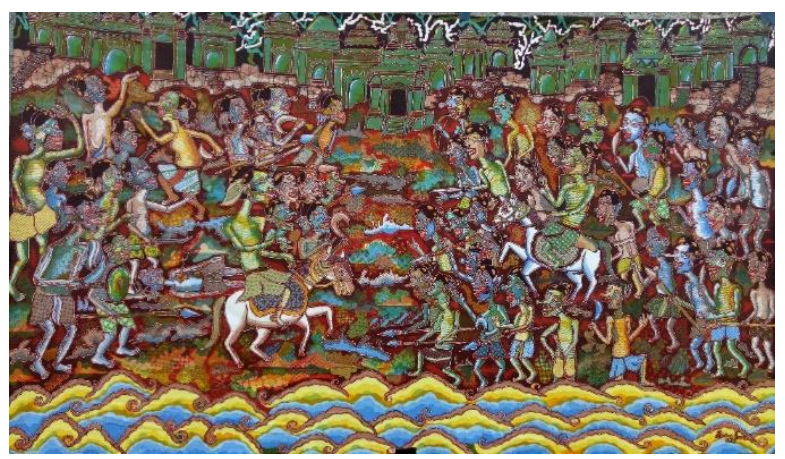

Gambar 5 : Judul karya : Perange Asmara, $105 \mathrm{~cm}$ x $180 \mathrm{~cm}$, teknik : Tutup celup , Lorodan, Media : Batik Tulis.

Dokumentasi : Stefanus Bintang Kumara, 2019

Ide dari karya ini terinspirasi dari wayang beber yang menceritakan tetang kisah pewayangan Panji. Dimana pada cerita ini Panji 
sedang menjalin asmara dengan Dewi Sekartaji dan disuatu ketika Dewi sekartaji di culik oleh Prabu Klana yang ingin menikahi Dewi Sekartaji. Panji atau yang digambarkan dengan tokoh Joko Kembang Kuning di utus oleh Prabu Brawijaya untuk menjemput dan membawa kembali ke Kediri. Jaka Kembang Kuning segera menjalankan tugas dengan membawa pasukan tempurnya. Pertarungan antara Jaka Kembang Kuning dan Prabu Klana pun dimulai. Pada karya ini digambarkan kejadian perang antara kedua kubu yang memperebutkan Dewi Sekartaji. Karya ini merubah susunan cerita, figur tokohnya, dan bentuk penyajian pada wayang aslinya.

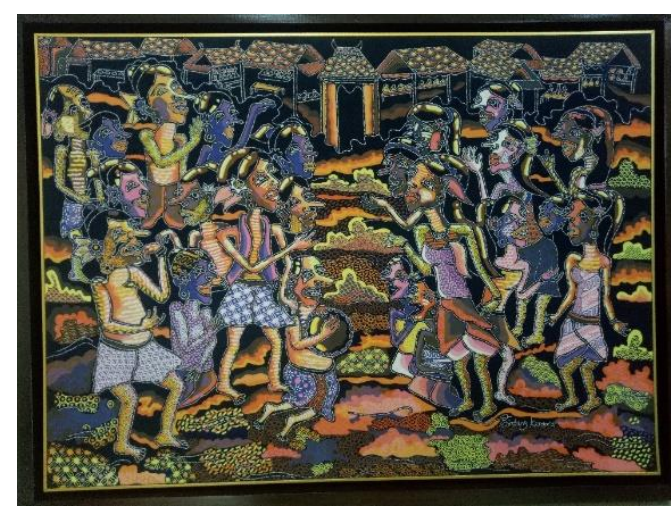

Gambar 6 : Judul karya : Nyamare Panji, $50 \mathrm{~cm} \mathrm{x}$ $70 \mathrm{~cm}$, teknik : Tutup celup, Lorodan, Media : Batik Tulis.

Dokumentasi : Stefanus Bintang Kumara, 2019

Pada karya ini menceritakan tentang penyamaran Panji sebagai pengamen. Tujuan Panji menyamar untuk mencuri perhatian Dewi Sekartaji dan membawanya pulang ke Kediri. Panji di utus oleh Prabu Brawijaya untuk mencari dan membawa pulang anaknya yaitu Dewi Sekartaji, barang siapa yang berhasil akan dijadikan suami anaknya. Dewi Sekartaji sendiri pergi dari kerajaan karena tidak mau di jodohkan dengan Prabu Klana. Sayembara itu dimenangkan oleh Panji. Karya ini menggambarkan Panji sedang mengamen bersama para prajurit di depan Dewi Sekartaji beserta dayang-dayangnya. Seting tempat pada karya ini menunjukan suasana pasar.

\section{KESIMPULAN}

Wayang beber me seni wayang yang berkembang di Jawa pada masa Kerajaan Majapahit, hingga di pengarui oleh agama Islam, terus berkembang di daerah-daerah tertentu seperti Pacitan dan Gunung Kidul. Dapat disebut wayang beber karena wayang ini merupakan lembaran kain atau kertas bergambar tokoh pewayangan dalam alur cerita Mahabaratha, Ramayana dan berkembang menjadi cerita Panji. Wayang ini memiliki beberapa alur cerita disetiap gulungannya sesuai adegan yang diperankan oleh tokoh wayang tersebut. Gambar-gambar tersebut dipertunjukan dengan cara membentangkan kain/kertas diatas peti kecil. Peti itu juga sebagai tempat penyimpanan wayang beber.

Seni tradisi harus terus dilestariakan dengan seiringnya teknologi yang akan terus berkembang dari zaman ke-zaman. Oleh karena itu warisan budaya masa lampau patut dikembangkan dan menjadi inspirasi untuk menghadirkan kemungkinan-kemungkinan baru dalam pengembangan seni khususnya pada wayang beber. Mengembangkan bentuk visual serta teknik merupakan bagian dari melestarikan warisan budaya itu sendiri.

Memindah bentuk wayang beber ke dalam batik merupakan salah satu wujud pengembangan yang bertujuan untuk menghidupkan seni tradisi, menumbuhkan minat masyarakat akan kesenian wayang beber, dan sebagai pembelajaran bagi masyarakat luas. Seni wayang dan batik akan terus berkembang jika ide-ide dan proses kreatif (inovasi) terus dilakukan secara berkelanjutan oleh masyarakat pendukungnya.

\section{DAFTAR PUSTAKA}

Ernawati, E. (2019). KAJIAN ESTETIKA SENI BATIK KONTEMPORER MELALUI KARYA KOLABORASI SENIMAN AGUS ISMOYO-NIA FLIAM. Studi Budaya Nusantara, 3(1).

Gustami, SP. (2004). Proses Penciptaan Seni Kriya, Program Penciptaan Seni Pascasarjana,Institut

Seni Indonesia Yogyakarta.

Hutcheon Linda. (2006). A Theory of Adaptation, Taylor \& Francis Group, New York, London. Kartika, Dharsono Sony. (2017). Seni Rupa Modern. Bandung: Rekayasa Sains.

Sayid.R.M. (1980). Sejarah Wayang Beber. Solo: Reksa Pustaka.

Susanto Sewan. (1980). Seni Kerajinan Batik Indonesia, Balai Penelitian dan Kerajinan.

Subandi.dkk. (2011). Wayang Beber Remeng Mangunjaya Gelaran Wonosari dan Wayang beber

Jaka Kembang Kuning Karangtalun Pacitan Serta Persebarannya Di Seputar Surakarta.Solo:ISI Press

Sumanto.dkk. (2011). Studi Komparatif Pertunjukan Wayang Beber Lakon Jaka Kembang Kuning Dengan Remeng Mangunjaya. Solo: ISI Press. 